\title{
Estimation of net-to-gross of among hydrocarbon field using well log and 3D seismic data
}

\author{
Sonny Inichinbia ${ }^{1}$, Peter O. Sule ${ }^{2}$, Halidu Hamza ${ }^{2}$, and Aminu L. Ahmed ${ }^{2}$ \\ ${ }^{1}$ Department of Physics, Ahmadu Bello University, Zaria, Nigeria \\ ${ }^{2}$ Department of Physics, Ahmadu Bello University, Zaria, Nigeria \\ ${ }^{*}$ Department of Geology, Ahmadu Bello University, Zaria, Nigeria
}

\begin{abstract}
We present quantitative estimates of net-to-gross of Amangi Field from seismically derived rock properties. We employed well log calibrated seismic inversion attributes using Rock Physics and prestack seismic (AVO) inversion. Crossplots of rock properties and attributes of the well log data from the target reservoirs were analyzed. The reservoir sands were found to have high P-impedances values comparable to the shales $\left(22,000 \mathrm{~g} / \mathrm{cm}^{3} \mathrm{ft} / \mathrm{s}-28000 \mathrm{~g} / \mathrm{cm}^{3} \mathrm{ft} / \mathrm{s}\right)$. Thus, P-impedance alone could not separate the sands from the shales while the S-impedance domain does. The sands are termed "hard" sands. This is indeed a classical case in the Niger Delta where the normal trend had been the sands having a lower P-impedance than the shales. A trend of increasing $N / G$ was observed in moving from the shale to the reservoir sands and decreasing $N / G$ in moving from the reservoir sands to the sealing shale. To further buttress this findings seismic AVO inversion for $V_{p} / V_{s}$ volume and $N / G$ volume and map were obtained from the $3 D$ seismic data. These indicated high $N / G$ values $(0.4-1.0)$ and low $V_{p} / V_{s}$ values $(1.6-1.8)$ for the reservoir sands across the field. The N/G map will be used to select possible locations for development wells.
\end{abstract}

Keywords: $H 1000$ and $H 4000$, inversion, net-to-gross, $P$-impedance, $S$ - impedance, $V_{p} / V_{s}$ ratio,

\section{Introduction}

There are development challenges in the data set of Amangi field, which include uncertainties about the distribution of reservoir properties (such as porosity and net-to-gross), the discrimination of hydrocarbon bearing sands from shales and more importantly, the separation of gas sands from brine saturated sandstones. Initial AVO inversion of anisotropic 3D prestack seismic data revealed that P-impedance could not discriminate gas sands from shale in this field. Therefore, a further transformation of impedance volumes to net-to-gross was performed to address these challenges.

There is increasing focus on hydrocarbon prediction from heterogeneous reservoirs. The Agbada Formation sandstones are heterogeneous and one useful parameter for quantification of the heterogeneity of sands is net-to-gross $(\mathrm{N} / \mathrm{G})$, which is the fraction of clean, permeable sand to the complete reservoir including reservoir sands and intercalating impermeable shales. The N/G is a reservoir parameter of interest for both fluid flow and geologic modelling [1]. N/G is a measure of the amount of sand or pay in the overall reservoir and is used to appraise reservoir quality and the economics associated with reservoir development.

As seismic based reservoir characterization technology is advancing in many cases lithology and porosity information derived from seismic inversion can be used to derive an estimate of N/G. In many cases this problem is nonunique due to accuracy of seismic inversion and the rock physics nature of the lithology and porosity prediction. Thus, as N/G estimates are often used for economic decision making, it is important to associate expected risk or confidence associated with the prediction [2]. [3] defined net-to-gross as the fractional volume of sand in the entire reservoir. It could be useful to estimate the fractional volume of pay in the reservoir.

The limitations of using low frequency 3D seismic data for detailed reservoir characterization are well recognized. Nonetheless, these data are very well suited for quantitative estimates of the net-to-gross, which is a reservoir scale property critical in reservoir characterization and development projects. The P-impedance inversion of 3D seismic data has been routinely used with varying success to estimate the $N / G$ in many clastic reservoirs. However, N/G is a scale dependent parameter. A reservoir zone can have high N/G at well log scale, but low N/G at seismic scale.

Nevertheless, the N/G is a useful parameter when we upscale from alternating thin beds of different lithologies and/or fluid saturations to an effective medium, during rock physics analysis of well log and seismic data. Indeed, when the shale baseline impedance can be estimated, the departure from this trend can be argued to represent a certain measure of the hydrocarbon saturated sand volume on the reservoir scale [3]. We take this technique a little step further by using both P- and S- impedance and applying them to the Amangi Field reservoirs where five appraisal wells are available for calibration. 


\section{Field Location and geology}

The field is located $70 \mathrm{~km}$ northwest of Port Harcourt within the north eastern corner of Licence OML 21 in the Greater Ughelli depobelt of the Niger Delta of Nigeria (Figure 1). It consists of alternating units of sandstone and shale, which makes it the major petroleum bearing stratigraphic unit. The Formation consists of silliciclastics of 2,500 m thick and are accumulated in delta-front, and fluvio-deltaic environments. The age of the producing sand intervals of this Formation ranges from Eocene to Pliocene and becomes progressively younger southward $[4,5]$.

In the lower Agbada Formation, shale and sandstone beds are deposited in equal proportion while the upper layer is mostly sand with minor shale intercalation. Due to the high sedimentation rates of this Formation, the sand is under-compacted. Deepwater channel and turbidite equivalents of this sand are found seaward. Agbada Formation which consists of hydrocarbon bearing sands and transgressive sealing shale is readily influenced by fault which provides pathway for petroleum migration. Hence, Agbada Formation forms structural traps and stratigraphic traps which help to accumulate hydrocarbon. The known onshore and near shore Tertiary reservoirs of the Niger Delta Basin are all units of the Agbada Formation, and most significantly this stratigraphic unit accounts for about $58 \%$ of the Basin recoverable oil reserves and $55 \%$ of the Basin recoverable gas reserves [6].

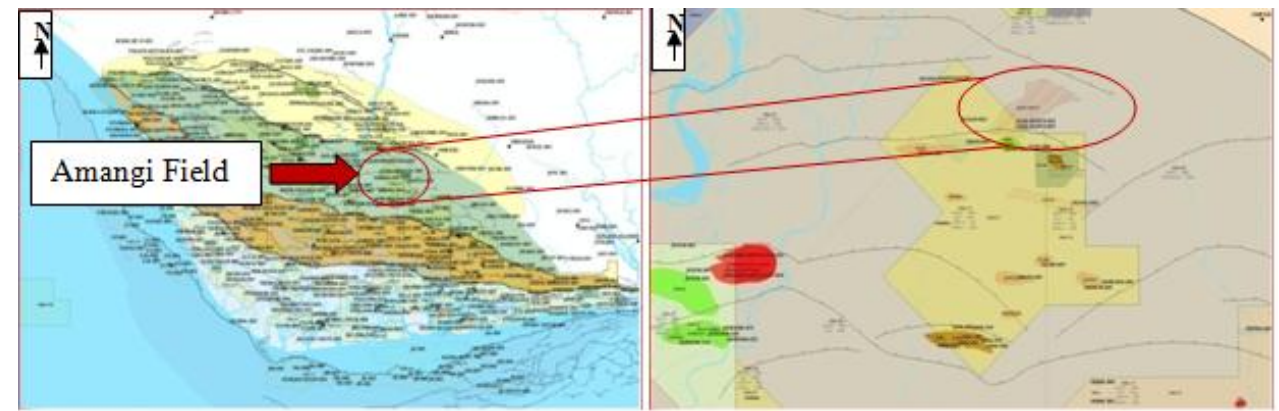

Figure 1. Map of the Niger Delta showing the study area. The encircled portion is the location of Amangi Field. (Source: Shell Petroleum Development Company of Nigeria Ltd.).

\section{Well log data}

The location of the six wells on the field is displayed in Fig. 2. Four of the wells are located in OML 21 while the rest two are in OML 53. The field is a unitized field. The two gas bearing sandstone reservoirs H1000 and H4000 were encountered in five wells in the Tertiary Agbada Formation of Amangi field of the Nigerian Delta. Extensive logging dataset were acquired and displayed in Table 1.

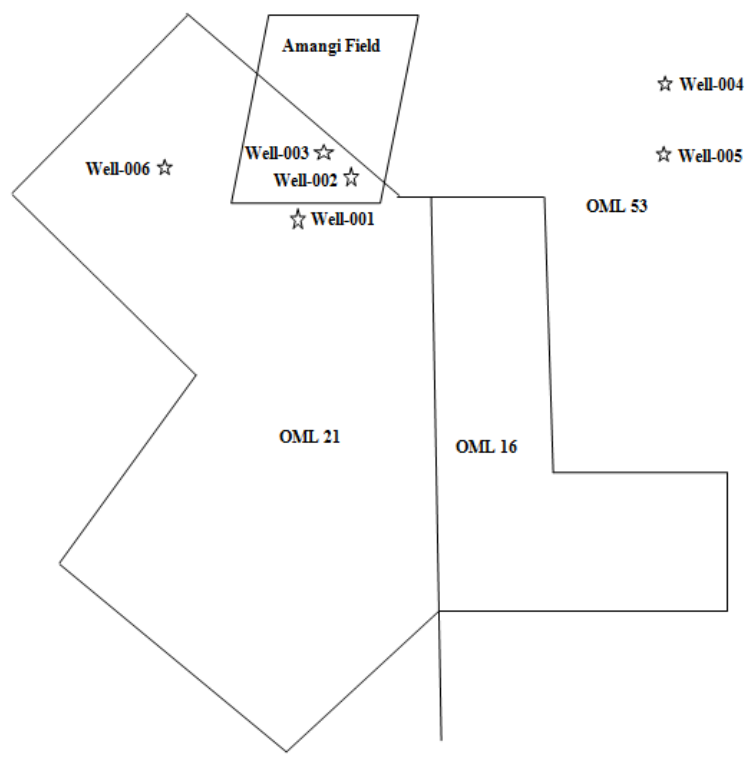

Figure 2. OML map of the study area showing the locations of the wells used in this study. Four wells are located in OML 21 whereas two wells are sited in OML 53. 
Table 1. Some wells in Amangi Field showing suite of logs in each well. Only Well-002 has a complete suite of good quality logs in the area, needed for this work.

\begin{tabular}{|l|l|l|l|l|l|l|l|l|l|}
\hline Well & $\begin{array}{l}\text { GR } \\
(\mathbf{A P I})\end{array}$ & $\begin{array}{l}\text { CALL. } \\
(\text { inches })\end{array}$ & $\begin{array}{l}\text { RESIS. } \\
(\mathbf{\Omega} \mathbf{m})\end{array}$ & $\begin{array}{l}\text { DEN. } \\
\left(\mathrm{g} / \mathrm{cm}^{\mathbf{3}}\right)\end{array}$ & $\begin{array}{l}\text { SONIC } \\
(\boldsymbol{\mu s} / \mathbf{f t})\end{array}$ & $\begin{array}{l}\text { PRESS. } \\
(\mathbf{p s i})\end{array}$ & FIT & $\begin{array}{l}\text { Checkshot } \\
(\mathrm{ms})\end{array}$ \\
\hline $\begin{array}{l}\text { Well- } \\
\mathbf{0 0 1}\end{array}$ & YES & YES & YES & NO & YES & NO & NO & YES \\
\hline $\begin{array}{l}\text { Well- } \\
\mathbf{0 0 2}\end{array}$ & YES & YES & YES & YES & YES & YES & YES & YES \\
\hline $\begin{array}{l}\text { Well- } \\
\mathbf{0 0 3}\end{array}$ & YES & YES & YES & YES & YES & YES & NO & NO \\
\hline $\begin{array}{l}\text { Well- } \\
\mathbf{0 0 4}\end{array}$ & YES & YES & YES & YES & YES & NO & NO & NO \\
\hline $\begin{array}{l}\text { Well- } \\
\mathbf{0 0 5}\end{array}$ & YES & YES & YES & YES & YES & NO & NO & NO \\
\hline
\end{tabular}

Fig. 3 shows the logs of well-002. This well was chosen among the five wells because it has the complete suite of logs for this study. The well log measurements include gamma ray, neutron, sonic, caliper, compressional velocity $\left(\mathrm{V}_{\mathrm{p}}\right)$, shear wave velocity $\left(\mathrm{V}_{\mathrm{s}}\right)$, and density $(\rho)$, as well as estimates of lithology and pore fluid content (volume fractions of shale, quartz, gas, and water components) for well-002.

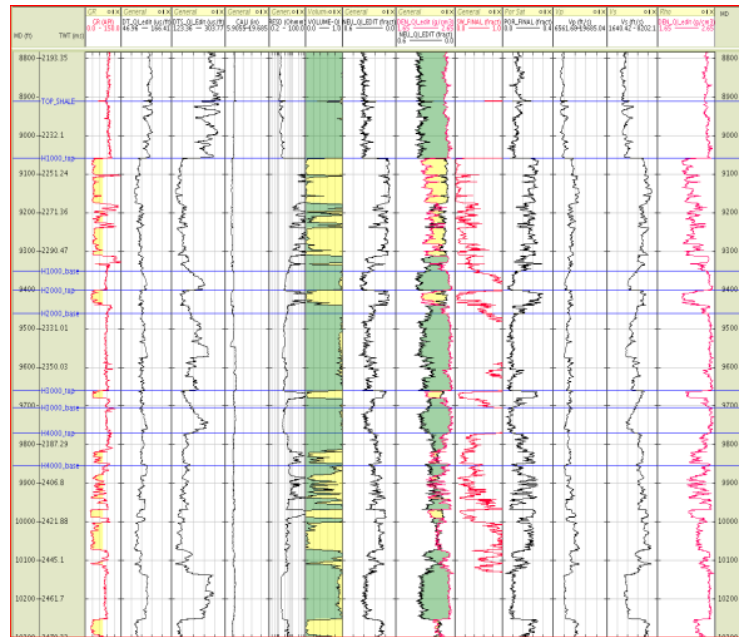

Figure 3. Wireline log signatures obtained in the area of study. Gamma ray, sonic, caliper, resistivity, volume shale, neutron, porosity, $V_{p}, V_{s}$ and density logs from one of the wells (Well-002) used in this study. The thick gas reservoir is characterized by higher resistivities and neutron-density crossover.

\section{Methodology}

The N/G estimation was done from the results of lithology $\left(\mathrm{V}_{\text {sand }}\right)$ estimation and porosity inversion. The data used are well log data (sonic, shear, density, clay content, porosity etc) and prestack seismic reflection data. The well log data were used for the calibration of rock properties to seismic attributes. The seismic data were subsequently used for facies classification and porosity estimation based on the calibration using the well logs [2]. Considering finely layered reservoirs from turbidite sequences, and modelling them with periodic techniques, AVO attributes were parameterized as functions of water saturation and the N/G. Similarly, seismic attributes were developed to respond to changes in the N/G [1].

\section{Analysis and discussions}

Crossplotting of rock properties was done in the targeted reservoirs (H1000 and H4000) involving some shales $200 \mathrm{~ms}$ above and beneath the reservoir intervals. However, caution was taken because the caprock shale might not necessarily be equivalent to the interbedded shale within the reservoirs. From the modelling of well $\log$ data, we tried to determine the sensitive parameters and the property spaces in which we could discriminate reservoir properties. From the P-impedance versus S-impedance crossplot we noticed "hard" sandstones (P-impedance in excess of about 22,000 g/ $\mathrm{cm}^{3} \mathrm{ft} / \mathrm{s}$ and S-impedance above 13,000 g/ $/ \mathrm{cm}^{3} \mathrm{ft} / \mathrm{s}$ ) in Fig. 
4. This crossplot shows major petrofacies and end member parallel trends in agreement with shale $(\mathrm{N} / \mathrm{G}=0)$ and gas sand $(\mathrm{N} / \mathrm{G}=1) \log$ impedance data.
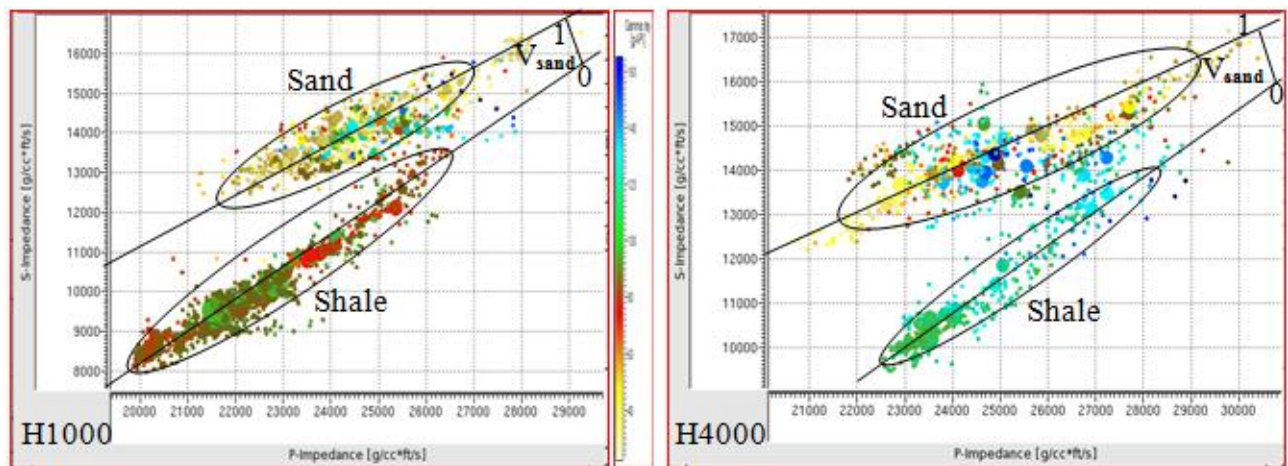

Figure 4. P-impedance versus $\mathrm{S}$-impedance crossplot showing major petrofacies in $\mathrm{H} 1000$ and $\mathrm{H} 4000$ respectively, colour coded with gamma ray. The plots indicate separate trends for sand and shale, but $\mathbf{P}$ impedance level alone cannot discriminate the lithologies.

From AVO analysis we can also distinguish the gas sand from sand and shale with the $\mathrm{V}_{\mathrm{p}} / \mathrm{V}_{\mathrm{s}}$ versus $\mathrm{P}$ impedance crossplot as shown in Fig. 5. Gas saturated sands in the wells show some amount of increase in Pimpedance. But the P-impedance space alone could not adequately delineate the rock types because of a reasonably large degree of overlap in the P-impedance value of the rock units. However, the shale dominated section and the sand dominated section are clearly identified and separated on the plot in the $\mathrm{V}_{\mathrm{p}} / \mathrm{V}_{\mathrm{s}}$ domain.
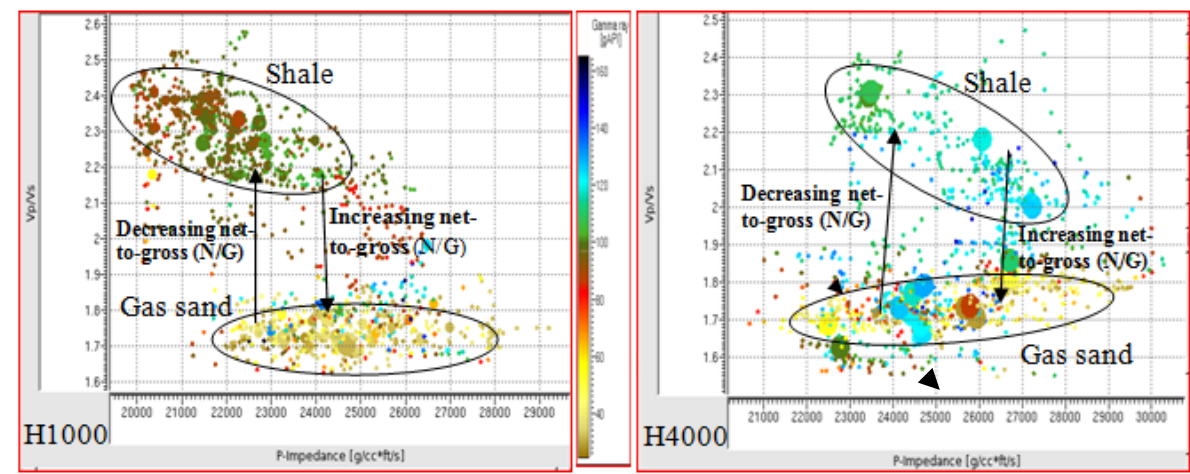

Figure 5. Crossplot of $P$-impedance versus $V_{p} / V_{s}$ for different facies and fluids in the target zones of study. The field data from the two main reservoir sands of well-002 showing relative positions of gas and water bearing sands and hard and soft shale.

So, the $\mathrm{V}_{\mathrm{p}} / \mathrm{V}_{\mathrm{s}}$ space proved adequate in separating the different rock types, as shown in Fig. 5. Note that the hydrocarbon sands span $\mathrm{V}_{\mathrm{p}} / \mathrm{V}_{\mathrm{s}}$ ratio from $1.6-1.8$, indicating some intercalation of shale within the reservoirs. The $\mathrm{V}_{\mathrm{p}} / \mathrm{V}_{\mathrm{s}}$ cutoff here is 1.8 . Thus, decrease in the $\mathrm{N} / \mathrm{G}$ causes a drastic increase of $\mathrm{V}_{\mathrm{p}} / \mathrm{V}_{\mathrm{s}}$ and very little shale intercalation will cause a significant increase in $\mathrm{V}_{\mathrm{p}} / \mathrm{V}_{\mathrm{s}}$ compared to homogeneous, clean sands (N/G $=1$ ). Note we used the reservoir sand together with some intervals of the sealing shale in the crossplots, and we can clearly observe that the gas saturated sands span a wide range of $\mathrm{V}_{\mathrm{p}} / \mathrm{V}_{\mathrm{s}}$ ratios, even close to 1.90 . An inverted $\mathrm{V}_{\mathrm{p}} / \mathrm{V}_{\mathrm{s}}$ section superimposed with the wells in the area of study is displayed in Fig. 9, to further buttress this point.

Hydrocarbon sands have $\mathrm{V}_{\mathrm{p}} / \mathrm{V}_{\mathrm{s}}$ ratio ranging from 1.6 to 1.9 . Gas saturated sands are clearly separated from the shales. The plot is colour coded with gamma ray. Leaving only the gas-saturated sands together with the cap-rock shales we clearly observe that the gas-saturated sands span a wide range of $\mathrm{V}_{\mathrm{p}} / \mathrm{V}_{\mathrm{s}}$ ratios. Some gas sands seem to have N/G values between 0.8 and 0.6 , causing $\mathrm{V}_{\mathrm{p}} / \mathrm{V}_{\mathrm{s}}$ close to 2 . This observation is consistent with a patchy saturation behaviour. The heterogeneities of the intercalating shales are causing a geologic control on the saturation pattern. Even though the gas saturation is uniform at the scale of the sandstone porosity, the effective medium will experience patchy saturation when the sand-shale layers are much smaller than the resolution of the sonic or seismic waves.

Using log data we show a crossplot of P-impedance versus gamma ray in Fig. 6. By this we establish a relationship between P-impedance and known rock properties within the specific target zones and within the frequency range of the inverted data set. The result shows that the lithologies could not be discriminated based 
on P-impedance space alone, but the gamma ray space does. In H1000 samples with low gamma ray are shown to contain high P-impedance which is diagnostic of the hydrocarbon bearing sands of this zone. Crossplots between $\mathrm{P}$-impedance and gamma ray show that the hydrocarbon sand and shale overlap on the impedance axis, the impedance contrast is weak. The sands are well separated from the shales on the gamma ray log.
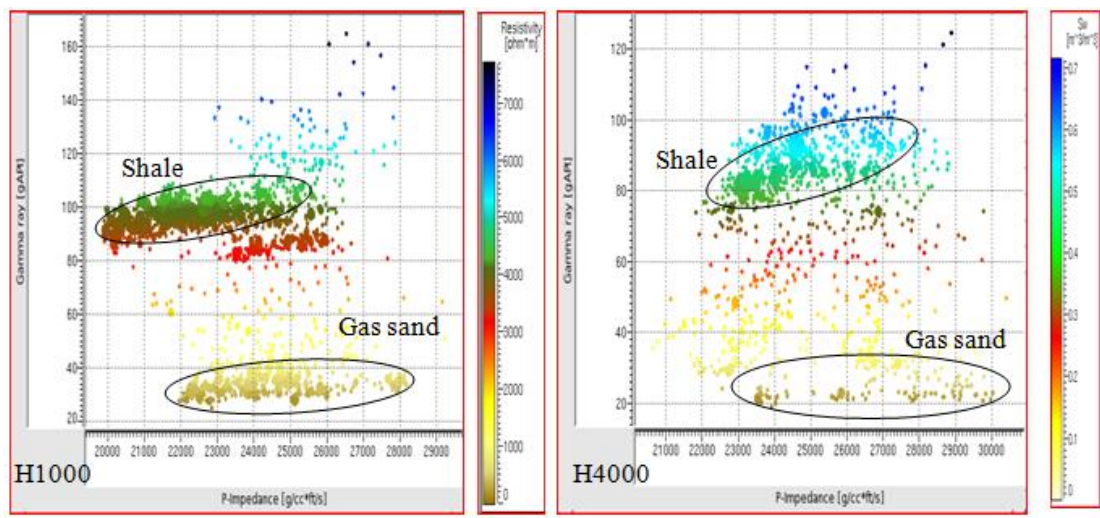

Figure 6. Crossplot between P-impadance and gamma ray for the target horizons to discriminate fluid and lithology - high P-impedance, high resistivity and low gamma ray indicate hydrocarbon sand. The large degree of scatter is as a result of the presence of clay.

Fig. 7 shows the crossplot of P-impedance versus porosity of the reservoir intervals from the well log data (well-002). The P- impedances drop drastically when the sands have low porosities, but increase slightly when the sands have high porosity. This is of course due to the relative contrast to the intercalating shale. The reservoir sand data points match nicely with the models for high N/G values $(0.8-1.0)$, and at the first glance it looks like the gas sands fall close to the line for homogeneous $(\mathrm{N} / \mathrm{G}=1)$ sandstone with $100 \%$ gas.
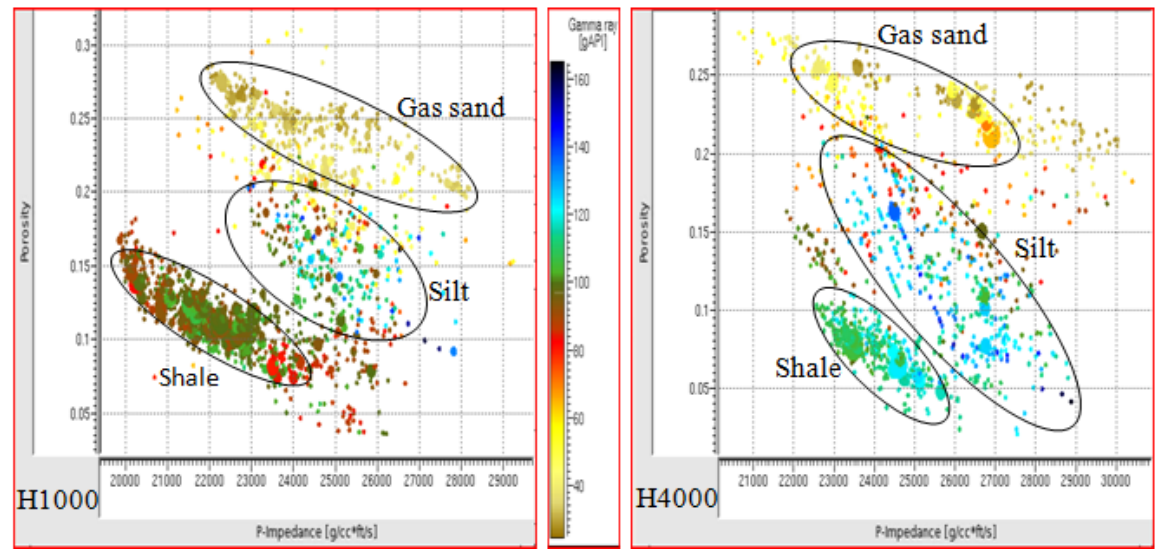

Figure 7. Crossplot of P-impedance versus porosity colour coded with gamma ray for quick lithology identification.

Due to the high sedimentation rates of the Agbada Formation, the sand is under-compacted. Note, that the gas sand fraction, $V_{\text {sand }}=1-V_{\text {shale. }}$ The total $N / G$ is estimated by integration over the gross reservoir thickness. Integrating $\mathrm{V}_{\text {sand }}$ over the gross reservoir thickness, $\Delta \mathrm{Z}=\mathrm{Z}_{\text {top }}-\mathrm{Z}_{\text {base}}$, leads to the estimate of net-togross for the specific target zone, where P-impedance and S-impedance data are available:

$N / G=\frac{\int_{\text {Ztop }}^{\text {Zbase }} V_{\text {sand }} \cdot d Z}{\Delta Z}$

where $V_{\text {sand }}$ is the gas sand fraction given by:

$$
V_{\text {sand }}=\frac{S I-b A I-a_{0}}{a_{1}-a_{0}}
$$


Where $b$ is the average slope of the shale slope $b_{0}$ and gas sand slope $b_{1}$, whereas $a_{0}$ and $a_{1}$ are the representative intercepts in the AI - SI crossplot involving all the available five wells as shown in Fig. 8. The inversion result is able to give us the N/G as we consider the crossplot of the P-impedance (acoustic impedance, $\mathrm{AI}$ ) and the S-impedance (SI) at the reservoir intervals and shale and sand base lines. The equation for the transformation is given as:

$$
\mathrm{N} / \mathrm{G}=(\mathrm{SI}+7233.313-0.765 * \mathrm{AI}) /(1440.34+0.517 * \mathrm{AI}+7233.313-0.765 * \mathrm{AI})
$$

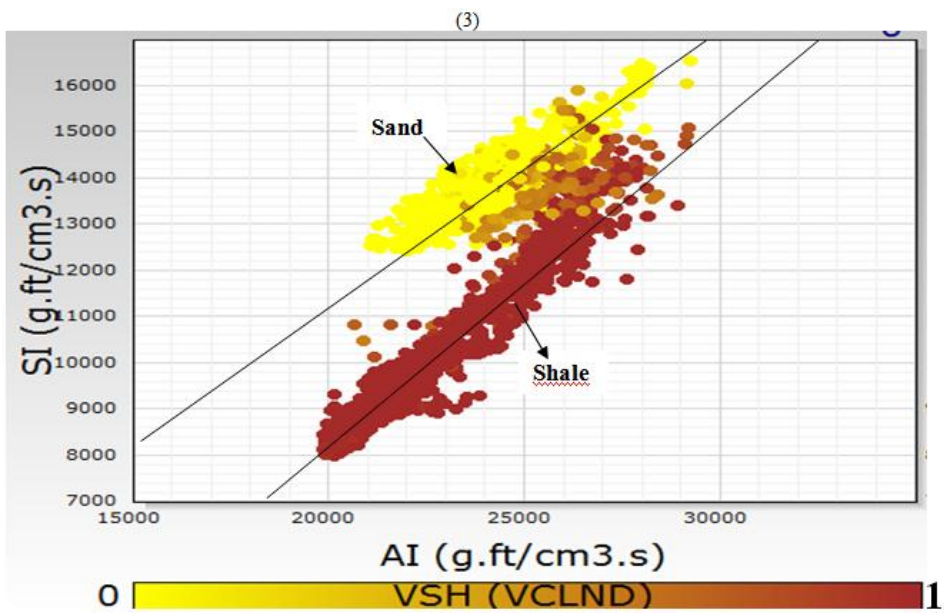

Figure 8. P-impedance versus $S$-impedance crossplot colour coded to $V_{\text {shale }}$ showing lithology separation via the $S$-impedance.

Gross thickness of H1000 is about $88.39 \mathrm{~m}(290 \mathrm{ft})$ and that of $\mathrm{H} 4000$ is about $25.60 \mathrm{~m}(84 \mathrm{ft})$. Reservoirs in this field are poorly consolidated sands. The two reservoir zones of interest, the H1000 sand and the H4000 sand occur at depths of $2702.05 \mathrm{~m}(8865.00 \mathrm{ft})$ to $2791.05 \mathrm{~m}(9157.00 \mathrm{ft})$ and $2919.07 \mathrm{~m}(9577.00 \mathrm{ft})$ to $2946.50 \mathrm{~m}(9661.00 \mathrm{ft})$ respectively, and display a high degree of heterogeneity and GUT/GDT variations (H1000: 9,058/9,335 scf/stb and H4000: 9,812/9,850 scf/stb). H4100 has OUT/ODT (9,879/9,942 scf/stb). These reservoirs are mildly overpressured $(0.66 \mathrm{psi} / \mathrm{ft}$ and saturated with condensate gas).

\section{Inversion}

To highlight amplitude variations with angle, the data was stacked in three angle ranges: near $\left(0^{\circ}-\right.$ $\left.10^{\circ}\right)$, medium $\left(11^{\circ}-20^{\circ}\right)$ and far $\left(21^{\circ}-30^{\circ}\right)$. P- and S- impedances were computed from the simultaneous inversion of these angle stacks, using seismic wavelets obtained from impedance logs $[7,8,9,10]$. Industry proprietary constrained sparse spike algorithm was used to invert the seismic data (three volumes of angle stacks) to P-impedance and $\mathrm{V}_{\mathrm{p}} / \mathrm{V}_{\mathrm{s}}$ ratio. A density volume was also computed, but in accordance with common practice was treated as a byproduct and not used further. Transformation from inversion results at each sample on every trace was solved as a geometric problem in P-impedance versus $\mathrm{V}_{\mathrm{p}} / \mathrm{V}_{\mathrm{s}}$ space.

The compaction trends were used to set up the hard and soft shale and clean wet and gassy sand endpoints. The P-impedance, $\mathrm{V}_{\mathrm{p}} / \mathrm{V}_{\mathrm{s}}$ pair was projected on to the line between hard shale and clean sand, scaled linearly in N/G ratio, see fig. 5. The total net footage from the inversion was compared with the well derived result, and adjustments made to the transforms to achieve a match between the two.

The result of this computation was a volume of N/G ratio. This was subsequently transformed to porosity using the transforms developed using well data. The resulting N/G volume is consistent with geological deposition model for hydrocarbon bearing reservoirs of the Niger Delta and the associated aquifers. Fig. 9 shows the inverted $\mathrm{V}_{\mathrm{p}} / \mathrm{V}_{\mathrm{s}}$ volume across the field with inverted $\mathrm{V}_{\mathrm{p}} / \mathrm{V}_{\mathrm{s}}$ sections from some of the wells overlain. The reservoir sandstones have $\mathrm{V}_{\mathrm{p}} / \mathrm{V}_{\mathrm{s}}$ values ranging from a low value of 1.6 to a high value close to 2.0 in the laminated zones while the shales have greater $\mathrm{V}_{\mathrm{p}} / \mathrm{V}_{\mathrm{s}}$ ratio from 1.9 to 2.4. Therefore a $\mathrm{V}_{\mathrm{p}} / \mathrm{V}_{\mathrm{s}}$ value of 1.9 should divide the sandstone formation from the shale dominated formations.

This seismically derived average $\mathrm{V}_{\mathrm{p}} / \mathrm{V}_{\mathrm{s}}$ value with a range of \pm 0.10 is higher than the 1.8 determined directly from the well $\log$ data (Fig. 5). This bulk $\mathrm{V}_{\mathrm{p}} / \mathrm{V}_{\mathrm{s}}$ shift is likely to be the result of slight picking errors on the top and base reflectors and also the systematic thinning of the isochron as frequency decreases. The immediately overlying shales are part of the formations and have a significantly lower $\mathrm{V}_{\mathrm{p}} / \mathrm{V}_{\mathrm{s}}$ than 2.1 , but markedly higher. Differentiation between the sandstones and shales is easy because they have separate $V_{p} / V_{s}$ values. $\mathrm{V}_{\mathrm{p}} / \mathrm{V}_{\mathrm{s}}$ value above 2.0 indicates a decrease in compaction and increasing porosity. In the very homogenous zones $\mathrm{V}_{\mathrm{p}} / \mathrm{V}_{\mathrm{s}}$ ratios are between $1.65-1.75$. 


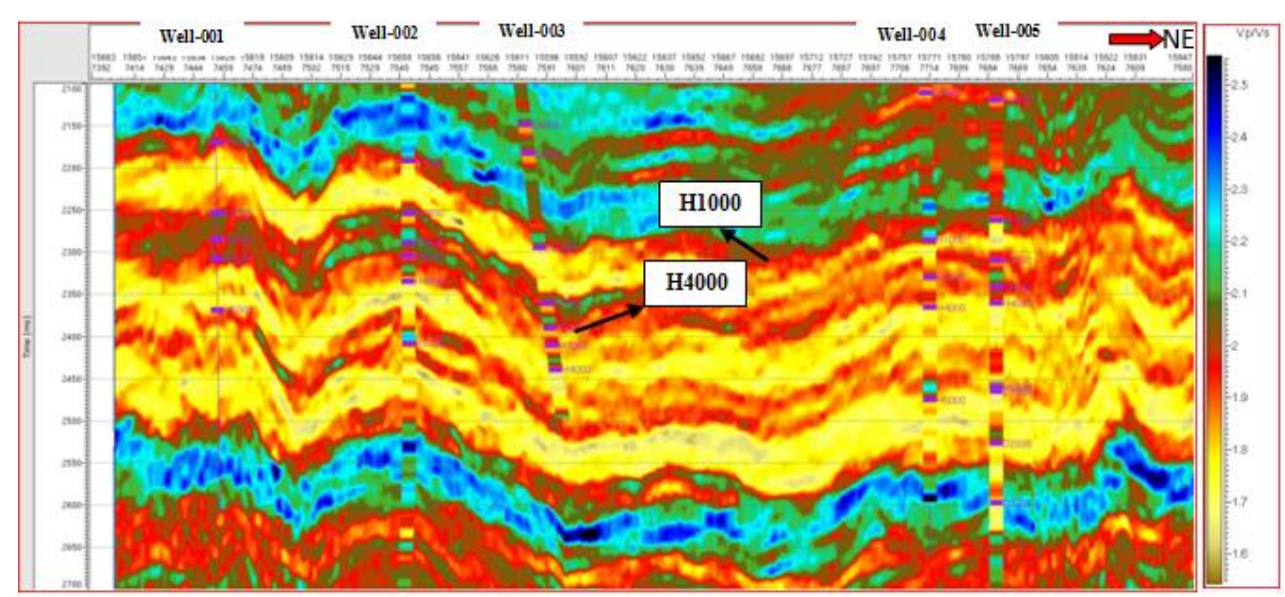

Figure 9. Inverted $V_{p} / V_{s}$ impedance volume with inverted $V_{p} / V_{s}$ of wells and tops overlain and colour coded with $V_{p} / V_{s}$. There is a good correlation between the $V_{p} / V_{s}$ section from the inverted 3D volume and those of the wells on the field superimposed on the inverted seismic section.

The reservoirs have a high N/G $(0.35-1.00)$ and low net-to-gross in the overlying and underlying shale. The gamma ray log inserted on the N/G section also confirms the delineated sand body within the reservoirs of interest. In addition the P-impedance log inserted at the well location also showed a high Pimpedance $\left(19,401.3 \mathrm{~g} / \mathrm{cm}^{3} \mathrm{ft} / \mathrm{s}-29,101.7 \mathrm{~g} / \mathrm{cm}^{3} \mathrm{ft} / \mathrm{s}\right)$ within the reservoir. This reservoir sand is actually "hard sand". Both logs showed quite good matches.

The crossplot of Fig. 5 shows how the P-impedance versus $\mathrm{V}_{\mathrm{p}} / \mathrm{V}_{\mathrm{s}}$ pair was resolved into N/G ratio for the gas bearing and brine cases. Net-to-gross is probably one of the unique properties of inhomogeneous turbidite reservoirs that can be rather qualitatively predicted even from a low resolution 3D seismic data [3]. Fig. 10 , which displays the inversion based N/G volume overlain with the $\log$ modelled $\mathrm{V}_{\text {sand }}$ and $\mathrm{V}_{\text {shale }}$ for the reservoir zones in the wells, is an ultimate confirmation of the proposed technique for the development of the field where the gross thickness could be resolved by the 3D seismic and the inverted impedance volume.

Based on side wall samples as well as the inversion based N/G data, the areas of N/G greater than 0.6 are most likely to be dominated by channel sands with milliDarcy range permeability. Areas of low N/G from $0.2-0.5$ represent thin sand and laminated levee deposits with permeability typically in the range of $100-300$ $\mathrm{mD}$ range. The orientation of the high permeability channel fairways can be seen in the section oriented in the northwest to southeast. The N/G values below 0.1 can be deemed nonpay from an economic point of view. The N/G section would be extensively utilized in selecting the new development well (NDW) locations because it is an important geologic factor that affects the seismic fluid predictability in reservoir sandstones. Reduced N/G will reduce fluid sensitivity of the reservoir sandstones by nonuniform (patchy) saturation.

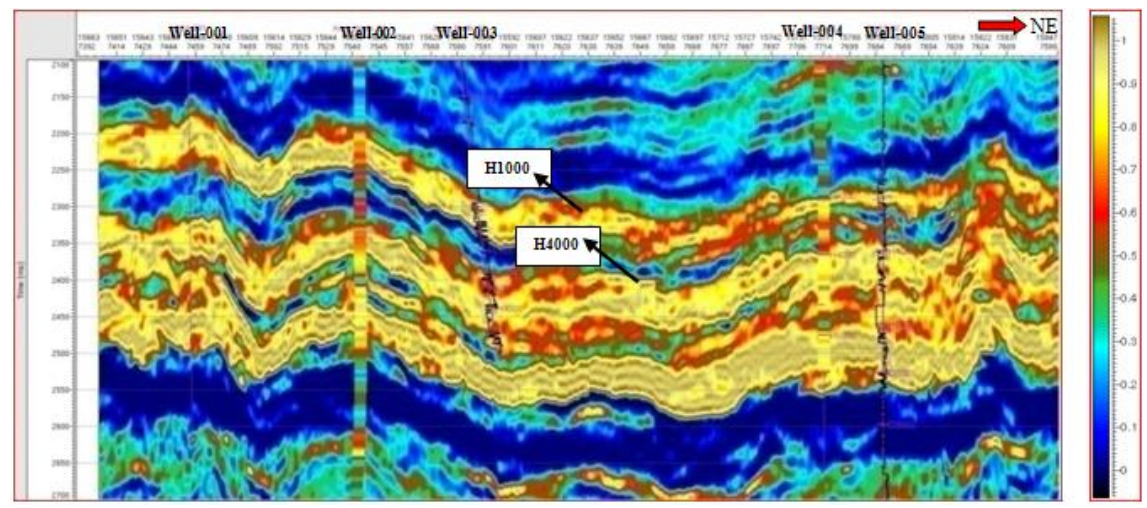

Figure 10. Net-to-gross volume derived from inverted impedance with impedance and gamma ray log from the wells overlain across the field. The section shows a good correlation and a thinning towards well004.

Some gas sands seem to have N/G value between 0.6 and 1.0 , causing $\mathrm{V}_{\mathrm{p}} / \mathrm{V}_{\mathrm{s}}$ close to 2 , a value more typical of brine saturated sands. This observation is consistent with a patchy saturated behaviour. The heterogeneities of the intercalating shales are causing a geologic control on the saturation pattern. Even though the gas saturation is uniform at the scale of the sandstone porosity, the effective medium will experience patchy saturation when the sand/shale layers are much smaller than the resolution of the sonic or seismic waves. 
Fig. 11 shows the N/G map of the entire field, indicating a high N/G in the proximal part of the field because of good quality sand which has been proven to be an aquifer from well-006 as this well met H1000 in the aquifer. As we prograde seaward the N/G decreases as a result of the presence of some shales which show some reduction in the N/G at the distal part of the N/G map. The N/G map would be used extensively to select drilling locations for development wells on the field.

Analysis of the data suggests preferential development locations are found in areas that have a combination of certain key rock properties. Specifically, optimal well placement should target areas of better porosity development and high siliceous mineralogical content. However, the N/G map of the entire field, indicate a high N/G in the proximal (upper) part of the field because of good quality sand which was proven to be an aquifer from well-006 as this well met H1000 in the aquifer. As we prograde seaward the N/G decreases as a result of the presence of some shales which shows some reduction in the N/G at the distal part of the N/G map.

We understand that a high degree of reservoir heterogeneity could make it challenging to predict a relationship between reservoir properties and the seismic response away from well control. The lateral distribution of this petrophysical parameter indicates that the quality of the H4000 sandstone reservoir shows some variability but basically low N/G at all well locations. This may indicate that reservoir connectivity is low and, accordingly, implies limitations of seismic resolution of these disconnected sand bodies.

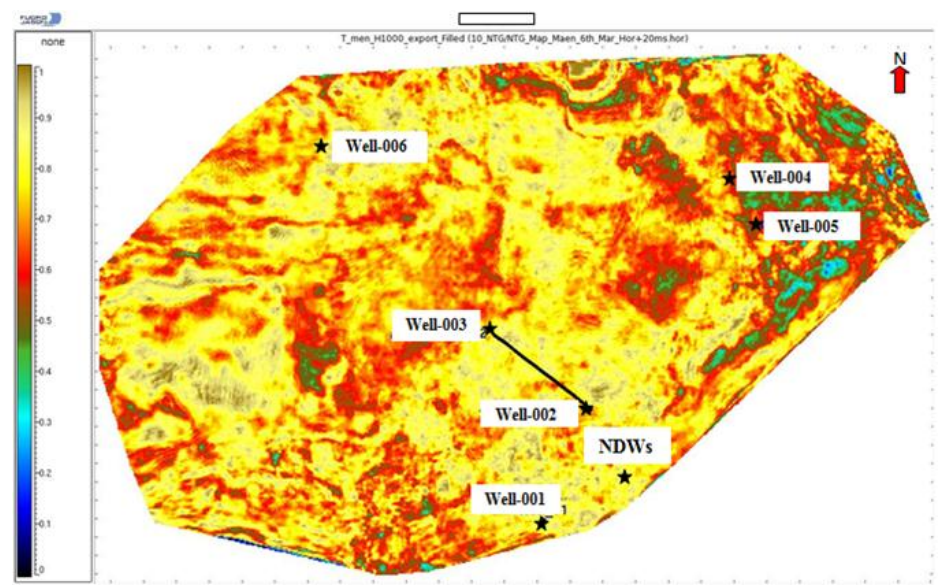

Figure 11. Inversion based net-to-gross map with the location of the wells in area of study superimposed. The map show high net-to-gross within the study, but the high net-to-gross in the proximal part was due to a good quality, huge sand package because of the seaward prograding trend of the sediments. Posssible location for new development wells (NDWs) is shown (distal to Well-002) at the distal part of the field.

\section{Conclusion}

The plots made from the well data demonstrated the importance of $\mathrm{V}_{\mathrm{p}} / \mathrm{V}_{\mathrm{s}}$ ratio in resolving poor quality gas sands and the aquifer, and demonstrated the futility of mapping the reservoir and aquifer with single term Pimpedance inversion. Seismic data were inverted for the properties of these reservoirs for intervals bounded by the interpreted seismic events. Varying N/G is an important geologic factor that affects the seismic fluid predictability in the reservoir sandstones. Reducing the N/G reduced fluid sensitivity of the reservoir sandstones. The N/G did so by nonuniform (patchy) saturation. This geologic factor is important to consider during fluid prediction from seismic data. The N/G shall be used to select locations for development wells, appraise reservoir quality and the economics associated with reservoir development. From this work, the field's sands are good quality sands and distal part of the field is the proposed location for development wells. The well and inverse transforms were based on detailed observations of the dependence of elastic properties on lithology and fluid changes. The N/G ratio shall be transformed to porosity using compaction trends and N/G to porosity transforms.

\section{Acknowledgements}

The authors are grateful to Shell Petroleum Development Company (SPDC) of Nigeria Limited for permission to publish this work. We are also thankful to Prahlad Basak, Francesca I. Osayande, Dike S. Robinson, Lucky M. Omudu, Temitope J. Jegede, Ufuoma Akpomeyoma and Obioma Umunna for their immense contributions all those who contributed by way of discussions and comments, to make this work a dream come true. 


\section{Reference}

[1]. K. T. Spikes, Statistical classification of seismic amplitude for saturation and net-to-gross estimates, The Leading Edge, 28(12), $2009,1436-1445$.

[2]. M. Sengupta, R. Bachrach, and N. Banik, Net-to-gross from seismic P and S impedances: estimation and uncertainty analysis using Bayesian statistics, $6^{\text {th }}$ International Conference \& Exposition on Petroleum Geophysics, "Kolkata 2006", 2006,1045 - 1049.

[3]. L. Vernik, D. Fisher, and S. Bahret, Estimation of net-to-gross from P and S impedance in deep water turbidites. The Leading Edge, 21(4), 2002, $380-387$.

[4]. J. I. Nwachukwu, and P. I. Chukwura, Organic matter of Agbada Formation, Niger Delta, Nigeria. The American Association of Petroleum Geologists Bulletin, 70(1), 1986, 48 - 55.

[5]. R. M. Bustin, Sedimentology and characteristics of dispersed organic matter in Tertiary Niger Delta: origin of source rocks in a deltaic environment. The American Association of Petroleum Geologists Bulletin, 72(3), 1988, 277 - 298.

[6]. K. C. Short, and A. J. Stauble, Outline of geology of Niger Delta. The American Association of Petroleum Geologists Bulletin, 51(5), 1967, $761-799$

[7]. P. Connolly, Elastic impedance: The Leading Edge, 18(4), 1999, 438-452.

[8]. C. Skelt, D. Glenn, S. Smith, C. Vu, S. Walden, P. Anderson, and B. Bacon, Incorporating rock property constraints and geological insights into seismic inversion for reservoir porosity and net-to-gross volumes, Annual Meeting, New Orleans, Society of Exploration Geophysicists, 2006, $1665-1669$.

[9]. P. Avseth, A. J. Wijngaarden, G. Mavko, and T. A. Johansen, Combined porosity, saturation and net-to-gross estimation from rock physics templates, Annual Meeting, New Orleans, Society of Exploration Geophysicists, 2006, 1856 - 1860.

[10]. P. Avseth, A. Jorstad, V. Aart-Jan, and G. Mavko, Rock physics estimation of cement volume, sorting, and net-to-gross in North Sea sandstones, The Leading Edge, 28(1), 2009, 98 - 108 